\title{
SUSTAINABLE AND ENVIRONMENTALLY FRIENDLY TRANSPORTATION: WHAT WE CAN LEARN FOR INDONESIA
}

\author{
Abdul Kudus Zaini ${ }^{1 *}$ \\ ${ }^{I}$ Faculty of Engineering, Islamic University of Riau, Riau 28284, Indonesia
}

(Received: November 2019 / Revised: December 2019 / Accepted: December 2019)

\begin{abstract}
Transportation plays an important role in improving the quality of urban life, in accordance with space, time and energy. However, there are lots of problems associated with transportation such as air pollution, traffic congestion, high fuel consumption, and accidents, which affects the survival of the surrounding environment. There is a close relationship between transportation and the environment in the development of infrastructure or facilities in supporting community activities following the process and results of its activities. In addition, the link between transportation and environment covers a wide spectrum with a rise in impact due to the existence of infrastructure that physically affects the facility's operation. Therefore, it is necessary to implement a sustainable development program to overcome the various problems that damage the environment such as the high conflicts of interests, diverse cultural structures, lack of human resources and social awareness within the community.
\end{abstract}

Keywords: Environment; Sustainable transport; Transportation

\section{INTRODUCTION}

Transportation plays an important role in improving the quality of life of people living in urban areas in accordance with the use of space, time and energy (Kii, Akimoto, \& Doi, 2014; Steg \& Gifford, 2005). However, there are lots of problems associated with transportation, such as air pollution, traffic congestion, high fuel consumption, and accidents. According to Moughtin and Shirley (2005), the traffic problems associated a city's transportation program is not overcome by building more new road networks which require significant costs and causes environmental problems.

Traffic congestion in big cities like Jakarta, Bangkok, and Mexico is commonly experienced by residents daily. However, the congestion in Bangkok is considered the worst amongst the major cities in the world. Based on a 1989 report from JICA (Japan International Corporation Agency), the average speed of vehicles on the metropolitan streets of Bangkok was $8.1 \mathrm{~km} / \mathrm{hour}$ during peak hours, which reduced to $4.8 \mathrm{~km} /$ hour in 2006 (Setchell, 1995). The main causes of this condition are rapid population growth, increase in the use of private vehicles, poor road network development, lack of investment in public transportation systems, weak planning and government decisions (Hokao \& Mohamed, 1999; Soehodho, 2017).

\footnotetext{
*Corresponding author's email: abdulkuduszaini@eng.uir.ac.id
} 
The construction of many new high-cost roads being carried out for the purpose of reducing traffic congestion will not actually solve the problem, but instead will increase the occurrence of congestion on other road sections. Even the construction of new roads in the city can cause damage to the environment and historic buildings, loss of habitat or plant species, damage to the urban landscape, and the growth of new activities that are not in accordance with planned activities.

The construction of new and expensive roads to reduce traffic congestion is incapable of solving this problem, instead, it tends to increase the occurrence of congestion on other sections. In addition, the construction of new roads damages historic buildings, urban landscape, and leads to loss of habitat or plant species, as well as the growth of unplanned activities.

Several steps are needed to ensure the environment, meets the living standards of humans and other living creatures. These steps include (1) developing technical policies, (2) increasing regional capacity in controlling vehicle emissions through the use of technology, (3) increasing the mechanism for monitoring and evaluating emissions, and (4) increasing the community's participation in achieving clean air.

It is necessary to develop air pollution control and technical policies as reference material for individuals, community groups, or related institutions. Policies to control air pollution from mobile sources include (1) the use of environmentally friendly fuels, (2) setting standards for the quality of motor vehicle exhaust emissions in accordance with developing technologies, (3) improve the application of environmentally friendly transportation management, (4) foster awareness and active role of the community, and (5) improving motor vehicle inspection and maintenance programs.

PP No. 41 of 1999 concerning Air Pollution Control indicates the existence of technical guidelines in implementing community empowerment through campaigns. Therefore, a preliminary understanding is needed in relation to community attitudes towards the existence of a sustainable transportation system at all levels such as academics, and non-governmental organizations that are expected to function as pressure groups. Government institutions are expected to function as implementers of proposed or determined policies.

\section{THE RELATIONSHIP BETWEEN TRANSPORTATION AND THE ENVIRONMENT}

The relationship between transportation and the environment is closely related and includes the development of transportation infrastructure or activities with positive impacts. Transportation plays an important role in the development of human needs which is important in places of work, shopping, business, and school environment. The transportation is also one of the measures that support a country's development.

Transportation plays an important role in city life in accordance with the use of space, time and energy. There are lots of problems caused by transportation such as pollution, traffic congestion, high fuel consumption, accidents, and many others. Moughtin and Shirley (2005), stated that the city traffic problem cannot be solved by building more cost-effective road networks. 


\section{THE ROLE OF TRANSPORTATION TO ENVIRONMENTAL DEGRADATION}

The relationship between transportation and the environment covers a very wide spectrum. The impacts are either due to the existence of transportation infrastructure that physically affects the surrounding environment or the facility's mode of operation. The environmental impacts are as a result of the prolonged issues associated with the transportation program along with the development of human activities (Ran \& Boyce, 2012).

The effect of air pollution is felt as a decrease in the health and performance of humans, animals, and plants which creates a decline in the environment (Banister, 2001). In 1994, the World Bank stated that air pollution in Jakarta led to the emergence of 1200 premature death, 32 million respiratory illness and 464 thousand cases of asthma and financial losses estimated at 500 billion rupiahs.

\subsection{Pollution}

The transportation technology in Indonesia is rapidly developing in accordance with the activities of modern society. However, behind the relationship harmony, there is a negative impact caused by land transportation facilities. These negative impacts include a decrease in the environmental quality which leads to a decrease in the quality of public health.

$\mathrm{CO}$ gas comes from the incomplete combustion of fossil fuels in the vehicle chamber. It tends to survive in the atmosphere for 1 to 5 years, with the ability to bind the haemoglobin in the blood 200 times greater than the power of oxygen $t$ and leads to death when the levels are above 60 percent. As a result of these pollution materials, which lead to the obstruction of oxygen flow in the blood, the respiratory system is damaged, thereby, making the lungs black. Lack of oxygen causes various diseases and psychological effects, namely colds, coughs, fever, asthma, headaches, stress, high blood pressure.

Pm10 is residual combustion in the form of dust and black smoke which damages the lungs and attacks the eyes when inhaled over a prolonged period. These dust particles also cause interference with the respiratory tract to cause infections.

In 2004, the level of environmental damage due to transportation activities exceeded the specified threshold. A total of 800 vehicles were tested and 50 percent exceeded the standard limits of the Governor's Decree No. 5 of 2004.

\subsection{Sustainable Transportation Policy}

According to Beatley and Newman (2013), basic understanding of sustainable development needs to be improved in the global context of any economy, to prevent damaging the environmental conditions. This understanding was developed through global socio-political processes in the last three decades of the 20th century. However, sustainability is the most diverse concept among professionals and academicians when discussing the future, and practice involves all disciplines irrespective of their professions.

According to Schubert and Láng (2005), Brundtland Report stated that 4 principles are the basis for scaling the global sustainability that needs to be applied simultaneously to future approaches, namely:

1) Eradication of poverty, especially in the third world is important for humanitarian reasons as an environmental issue.

2) Developed countries need to reduce their consumption rate of natural resources and waste production. 
3) Global cooperation on environmental issues is no longer a voluntary choice.

4) Changes to sustainability are implemented using a community-based approach that seriously involves local culture.

There are many strategies/mechanism used to achieve sustainable urban transportation. According to Blowers (2013), there are 4 (four) principles of the mechanism needed to achieve a sustainable transportation strategy. These are as follows:

1) A regulatory mechanism that aims to limit the level of pollution generated by vehicles.

2) Financial mechanisms, through energy taxes on the consumption of fuel and emissions for air pollution.

3) Encourage the research and development of efficient vehicles in the use of fuel, as well as

a) Alternative transportation technologies.

b) The existence of integration in land use planning to minimize the distance achieved, encourage the use of public transportation and improve the ease of achieving its facilities.

However, these four principles above are utilized in developed countries and require further adjustment when adopten in developing countries such as Indonesia. The United Kingdom has also developed 8 (eight) strategies to achieve sustainable transport policies applicable to cities around the world. These strategies are as follows:

1) There is integration between government policies in the field of land transportation with priority to the reduction of the increased proportion of trips vehicles that do not damage the environment.

2) Achieve standards that affect health and environmental quality.

3) Improve the quality of city life by reducing the dependence of motorized vehicles.

4) Increase the number of vehicles used for private trips that do not have a lot of negative impacts on the environment, while, utilizing the best use of the existing infrastructure.

5) Avoid the use of land transportation in areas with high conservation value, crocodiles and landscaping.

6) Reduce carbon dioxide emissions from vehicles.

7) Reduce the use of non-renewable materials for the manufacture of infrastructure and the vehicle industry.

8) Reduce noise pollution from vehicles

Developing countries need to utilize the four principles of Blowers and the transportation strategy of the British state, in the transportation field. In Indonesia, many efforts have been conveniently utilized in the environmentally friendly transportation system. Some of these strategies are as follows:

1) Procurement of convenient public vehicles (city buses, electric trains, trams and so on).

2) Replacement of fuel with ethanol and biogas.

3) The use of solar energy to run vehicles.

4) Promoting the use of bicycles and walking.

5) Implementation of a traffic calming system on several roads in the downtown area and settlements. In this system, vehicles are slowed down, to prevent accidents with certain types allowed to pass. This method is also obtained by narrowing the width of the road, using material meant for non-asphalt roads. The application of a transit-oriented development system is concentrated in public places such as banks, markets, shops, offices, restaurants, etc. In addition, it is also easily integrated, and accessible on foot or public transportation system, thereby reducing the use of private vehicles. 
The various methods utilized in developed countries has not been applied in Indonesia, with high dependence on private vehicles. This is because to the system and condition of public transportation is currently unable to fulfil the level of comfort desired by users, therefore, traffic jams in big cities like Jakarta, Bandung and Surabaya are unavoidable. There is a possibility of increasing the number of cities affected by traffic congestion, assuming this issue is not properly addressed. Moreover, the phenomenon of the development of residential areas that are increasingly high is in sub-urban areas (suburbs), due to the poor implementation of public transportation facilities by the government. This is seen from the rampant problems of public transportation such as demands for tariff increases, high cost of spare parts, low quality of service to passengers, decreasing number of operating fleets, many others.

\section{THE FACTORS OF ACHIEVING SUCCESS}

The factors that need to be undertaken by the government to ensure the successful implementation of the program include the following.

1) Joint commitment

A joint commitment is needed by the government and city residents to enable the success of the program. A well established a joint commitment between the Government and the citizens of the city tend to provide significant progress on the development of the planned program.

2) Strengthening of institutions in managing air quality

Institutions that work in these fields are given basic reinforcement in the management of air quality, especially those that are part of the supervision. Its human resources and equipment need to be strengthened.

3) Strengthening law enforcement

The law enforcement needs to be strengthened by apprehending violators, with each processed in accordance with imposed sanctions and fines. Law enforcement is also carried out when conducting periodic tests on each vehicle tested to obtain a certificate.

4) Coordination

The success of the program is not only dependent on a person but fostered between stakeholders. To maintain the collaboration and success of this program, overall internal and external coordination is an important key.

5) Involving stakeholders

Initially, city residents were the object of the policy, now stakeholder involvement is an important part in conducting public consultations in every activity carried out by the government to increase the amount of clean air within a community.

6) Periodic monitoring

Every program that is carried out needs to be monitored regularly. This is done to get consistency from the programs that have been achieved and can be improved better. Periodic monitoring is provided, among others, by conducting spot tests regularly.

\section{CHALLENGES IN IMPLEMENTATION}

The challenges in implementing a sustainable transportation program are as follows. Firstly, the complexity of urban environmental transportation problems and the high conflicts of interest in their applied field. The problem of transportation in urban areas which refers to air pollution is complex and diverse. Some of the factors responsible for air pollution are the low quality of vehicles that are not well maintained due to expensive spare parts and maintenance costs, lack of equipment that control pollution, poor means of transportation that are cheap, comfortable 
and humane, as well as the various societal problems. In addition, the low awareness of the public on the dangers of pollution with a given perception tends to absorb public awareness by 40 percent.

Secondly, a diverse cultural structures and strata of society. The cultural structure and strata of the diverse societies create obstacles associated with socialization and approach. Characteristics of a community approach in Indonesia are usually conducted through influential leaders, therefore, many diverse strata of society in conducting socialization need to be conducted in a non-uniform approach to each region.

Thirdly, the lack of community awareness. The recognition of public awareness is still relatively low. This condition is quite difficult in controlling air pollution, therefore, the government needs a spot/walk monitoring process. Last, limited resources regarding human expertise/capability and equipment financing, are a big challenge. To address this, collaboration with the private sector and training to improve these resources are conducted.

\section{REFERENCES}

Banister, D. (2001). Transport planning. In Handbook of transport systems and traffic control (pp. 9-19): Emerald Group Publishing Limited.

Beatley, T., \& Newman, P. (2013). Biophilic cities are sustainable, resilient cities. Sustainability, 5(8), 3328-3345.

Blowers, A. (2013). Pollution and waste-a sustainable burden? In Planning for a Sustainable Environment (pp. 81-104): Routledge.

Hokao, K., \& Mohamed, S. S. (1999). Traffic impact mitigation for new developments: A way to reduce traffic congestion in major cities. Transport and Communications Bulletin for Asia and the Pacific, 68, 1-32.

Kii, M., Akimoto, K., \& Doi, K. (2014). Measuring the impact of urban policies on transportation energy saving using a land use-transport model. IATSS Research, 37(2), 98109.

Moughtin, C., \& Shirley, P. (2005). Urban design: green dimensions: Routledge.

Ran, B., \& Boyce, D. (2012). Modeling dynamic transportation networks: an intelligent transportation system oriented approach: Springer Science \& Business Media.

Schubert, A., \& Láng, I. (2005). The literature aftermath of the Brundtland report 'Our Common Future'. A scientometric study based on citations in science and social science journals. Environment, Development and Sustainability, 7(1), 1-8.

Setchell, C. A. (1995). The growing environmental crisis in the world's mega cities: the case of Bangkok. Third World Planning Review, 17(1), 1.

Soehodho, S. (2017). Public transportation development and traffic accident prevention in Indonesia. IATSS Research, 40(2), 76-80.

Steg, L., \& Gifford, R. (2005). Sustainable transportation and quality of life. Journal of transport geography, 13(1), 59-69. 